\title{
Aproximações entre governança colaborativa e ação comunicativa: uma proposta analítica de estudo
}

\author{
Lindsay Teixeira Sant'Anna 12 \\ Valderí de Castro Alcântara ${ }^{3}$ \\ José Roberto Pereira 1 \\ Mônica Carvalho Alves Cappelle ${ }^{1}$ \\ Dany Flávio Tonelli ${ }^{1}$ \\ 1 Universidade Federal de Lavras / Departamento de Administração e Economia, Lavras / MG - Brasil \\ 2 Faculdade Adventista de Minas Gerais, Lavras / MG - Brasil \\ 3 Universidade do Estado de Minas Gerais, Unidade Cláudio / MG - Brasil
}

Pode-se dizer que os esforços do gerencialismo não conseguiram apresentar grandes mudanças nos padrões das relações entre Estado centralizador e sociedade. Com isso em vista, o objetivo desta pesquisa foi propor uma abordagem analítica, a partir das aproximações entre governança colaborativa (GC) e teoria da ação comunicativa (TAC), para investigar práticas de colaboração comunicativa (CC) entre Estado e sociedade. Na busca pelas intersecções entre os pressupostos teóricos da GC e da TAC, identificaram-se quatro constructos teóricos para um cenário colaborativo: a) multiplicidade de atores; b) interdependência; c) processo deliberativo inclusivo; e d) busca pelo consenso. Os achados do estado da arte da GC e das obras clássicas habermasianas demonstraram que os pressupostos de uma CC viabilizam ambientes propícios a uma participação social inclusiva. Discute-se que é possível construir espaços propícios a uma CC entre Estado e sociedade, onde haja igualdade de participação entre os interessados, na busca por um entendimento compartilhado capaz de apontar soluções práticas para problemas públicos.

Palavras-chave: democracia; relações Estado-sociedade; colaboração comunicativa.

\section{Aproximaciones entre gobernanza colaborativa y acción comunicativa: una propuesta analítica de estudio}

Los esfuerzos del gerencialismo no pudieron presentar grandes cambios en los patrones de las relaciones entre Estado centralizador y sociedad. El objetivo de esta investigación es proponer un enfoque analítico, a partir de las aproximaciones entre la gobernanza colaborativa (GC) y la teoría de la acción comunicativa (TAC), para la investigación de prácticas de colaboración comunicativa (CC) entre Estado y sociedad. En la búsqueda por las intersecciones de los presupuestos teóricos de la GC y de la TAC, se identificaron cuatro constructos teóricos para un escenario colaborativo: multiplicidad de actores, interdependencia, proceso deliberativo inclusivo y búsqueda del consenso. Los hallazgos de las obras clásidas de Habermasian y de vanguardia de GC demostraron que los supuestos de CC permiten entornos propicios para la participación social inclusiva. Se discute que es posible construir espacios propicios a una CC entre Estado y sociedad, donde haya igualdad de participación entre los interesados, en la búsqueda de un entendimiento compartido capaz de apuntar soluciones prácticas para problemas públicos.

Palabras clave: democracia; relaciones Estado-sociedad; colaboración comunicativa.

\section{Intersections between collaborative governance and communicative action: an analytical proposal}

The New Public Management failed to present significant changes in the patterns of relations between the centralizing state and society. This research proposes an analytical approach based on the interactions between collaborative governance (CG) and communicative action theory (CAT), in order to study communicative collaboration (CC) practices involving the state and society. When looking for intersections among the theoretical assumptions in CG and CAT, the study identified four theoretical constructs that contribute to a collaborative scenario: multiplicity of actors, interdependence, inclusive deliberative process, and seeking consensus. The findings based on cutting-edge CG theory and on Habermas' classic works demonstrate that CC assumptions enable environments conducive to inclusive social participation. The article argues that it is possible to build spaces conducive to communicative collaboration between the state and society, where there is equal participation among actors seeking shared understanding leading to practical solutions to public problems.

Keywords: democracy; state-society relationships; communicative collaboration. 


\section{INTRODUÇÃO}

Nas várias transformações nas relações Estado-sociedade das últimas décadas, observa-se a predominância da racionalidade instrumental com finalidade econômica. O modelo burocrático sofreu críticas por sua excessiva via racional-instrumental. Entretanto, os movimentos posteriores não foram diferentes. A nova gestão pública (new public management - NPM), incorporada na administração pública brasileira em meados dos anos 1990, procurava substituir o modelo engessado burocrático, excessivamente hierarquizado. Isso inspirou o formato da chamada administração pública gerencial com foco em algumas características praticadas no setor privado a ser implantadas no setor público, como o aumento da eficiência, a busca pelos resultados e a responsabilização dos atores políticos, o movimento gerencialista não logrou êxito em boa parte de seus objetivos (Bryson, Crosby, \& Stone, 2014; Kissler \& Heidemann, 2006; Matias-Pereira, 2010). No entanto, percebeu-se que há a necessidade de uma ação conjunta entre Estado, sociedade civil e mercado na condução da gestão pública (Kissler \& Heidemann, 2006), na criação de valores, além de eficiência e eficácia, por meio de processo colaborativo e democrático (Bryson et al., 2014). Contudo, a tomada de decisão ainda se perpetuou centralizada no Estado.

Nesse contexto, o conceito de governança colaborativa (GC) vem sendo alvo de debates crescentes na literatura internacional (Bryson, Crosby, \& Stone, 2015), embora no Brasil os estudos sobre GC ainda sejam incipientes (Sant'Anna, Tonelli, \& Abbud, 2016; Tonelli, Sant'Anna, Abbud, \& Souza, 2018). Nessa nova forma de governança, o Estado não mais se sobrepõe aos outros atores parceiros, mas se coloca em um mesmo nível, em uma estrutura de diálogo e construção conjunta de decisões (Ansell \& Gash, 2008).

Elegendo a colaboração como indispensável aos sistemas de governança, é notório o interesse recente da literatura internacional em torno da abordagem da GC. As principais abordagens apresentam as características de um arranjo colaborativo (Ansell \& Gash, 2008); propõem a GC como um modelo normativo ideal, mas que ainda não é uma realidade (Freeman, 1997); apresentam as condições necessárias para o desenvolvimento de parcerias colaborativas (Foster-Fishman, Berkowitz, \& Lounsbury, 2001); analisam as redes como estruturas de governança e apresentam as condições para a construção da capacidade colaborativa (Sullivan, Barnes, \& Matka, 2006; Weber \& Khademian, 2008; Weber, Lovrich, \& Gaffney, 2007); exploram a abertura ou o fechamento político para os movimentos sociais na busca pela influência na tomada de decisão (Newman, Barnes, Sullivan, \& Knops, 2004); e propõem elementos para um regime de GC (Emerson, Nabatchi, \& Balogh, 2012).

Para Bingham (2010) e Purdy (2012), a GC surge como proposta emergente em substituição às abordagens tradicionais de comando e controle, inclusive de governança pública, onde se prioriza a mera participação formal. Na GC importam muito mais os valores construídos e as trocas entre os envolvidos do que a contabilização das atividades (Bryson et al., 2015). Com ênfase no processo de decisão coletiva, a GC pode ser compreendida como arranjo que envolve tanto atores públicos como privados em um processo de deliberação inclusiva, com vistas ao consenso, na busca pela solução de problemas públicos complexos (Ansell \& Gash, 2008; Robertson \& Choi, 2012).

Paralelamente, a teoria da ação comunicativa (TAC) de Jürgen Habermas tem sido muito utilizada para fornecer bases teóricas para a construção do diálogo público mediante formas participativas da sociedade. Na administração, a busca pelas contribuições de Habermas ocorre principalmente a partir dos estudos da gestão social, como Tenório (1998, 2005) e Alcântara e Pereira (2017). Tenório (1998, 
2005) define gestão social a partir dos elementos da ação comunicativa de Habermas. No campo dos estudos organizacionais, Habermas é explorado nos debates sobre racionalidade, ética do discurso, linguagem e ação comunicativa e na afiliação à Escola de Frankfurt - nesse caso, Habermas também é criticado pelas concepções de racionalidade comunicativa, consenso e modernidade (Couto \& Carrieri, 2017; Lara \& Vizeu, 2017). Em geral, na administração pública, Habermas fundamenta debates sobre esfera pública, sociedade civil, democracia deliberativa, participação e relações entre Estado, mercado e sociedade civil. Abreu (2010, pp. 17-18) coloca que "Habermas, enquanto representante da Escola de Frankfurt, carrega um forte teor crítico em suas elaborações" que se abre à importância da emancipação no âmbito da administração pública.

Da mesma forma que a TAC critica a hegemonia da racionalidade instrumental, a GC se posiciona contrariamente ao modelo tradicional de estruturas governamentais inadequadas e incapazes de lidar com os desafios públicos, centrados em estruturas hierárquicas, burocráticas, presas a rotinas e a objetivos limitados (Innes \& Booher, 2010). Por outro lado, muitas vezes o modelo que se propõe para maior participação dos interessados é uma colaboração entendida como o ato de reunir um grupo de pessoas para cooperar diante de uma finalidade específica, tão somente, ao invés de encontrar as condições para uma racionalidade colaborativa (Innes \& Booher, 2010) de veracidade, retidão e inteligibilidade (Habermas, 2012a). A proposta de governança que se procura apresentar neste artigo se baseia em uma colaboração comunicativa (CC) que não se confunde com outros tipos de sentidos genéricos que são atribuídos à palavra colaboração. Innes e Booher (2010) alertam exatamente para isso quando explicam que, muitas vezes, a colaboração também é usada como processo de barganha ou de cooptação. A CC se propõe a explorar opiniões diferentes e diversas e levá-las em consideração na tomada de decisões, isto é, superando a ideia de agregação em prol da visão de possibilidades de deliberação pública entre diferentes atores (Habermas, 1997).

Assim, esta pesquisa procurou responder a seguinte questão:

- A partir das limitações do gerencialismo na administração pública, como identificar práticas de colaboração comunicativa (CC) entre Estado e sociedade?

Nesse contexto, o objetivo deste artigo é propor uma abordagem analítica, a partir das aproximações entre a governança colaborativa (GC) e a teoria da ação comunicativa (TAC), para a investigação de aspectos relacionados à colaboração comunicativa (CC) entre Estado e sociedade.

Delimitar as intersecções entre ambas as teorias pode auxiliar estudiosos e administradores públicos na reflexão sobre uma nova maneira de diálogo entre os diversos interessados nos resultados práticos das discussões. Outra importante contribuição é que se para Andion (2012) o que ainda se encontra é a ausência de grandes mudanças nos padrões de relação entre Estado e sociedade, a contribuição deste artigo vai exatamente na direção de introduzir novas possibilidades de diálogos entre eles. A CC é entendida neste estudo como uma interação dialógica entre o poder administrativo (representado pelo sistema estatal) e o poder comunicativo (próprio do mundo da vida), em que se busca alcançar decisões deliberativas mediadas por argumentos racionais fundamentados na veracidade, na retidão e na inteligibilidade entre os atos de fala dos envolvidos, em prol de um consenso. No mais, CC constitui um conceito preliminar posto no campo de debates (comunidade de intérpretes de acadêmicos e praticantes) para ser desenvolvido a partir de novas contribuições teóricas e empíricas. 
Assim, este ensaio teórico e exploratório da literatura nacional e internacional apresenta discussões sobre GC, os fundamentos teóricos da TAC e suas interfaces para a construção de uma proposta analítica para o estudo da CC.

\section{FUNDAMENTOS DA GOVERNANÇA COLABORATIVA}

Em um mundo de constantes mudanças, complexo, com diversos interesses em jogo, já não cabe mais um modelo de administração pública centralizador e burocrático. A falta de interesse em compartilhar informações com a sociedade, o temor da ingerência política, o comportamento orientado somente a fins econômicos e o alto controle dos processos têm refletido uma tendência de predomínio da racionalidade instrumental (Innes \& Booher, 2010). O resultado é a dificuldade de aceitação pública das decisões (Purdy, 2012; Siddiki, Carboni, Koski, \& Sadiq, 2015), a exclusão de minorias (McDougall, Leeuwis, Bhattarai, Maharjan, \& Jiggins, 2013) e o não atendimento às demandas (Ansell \& Gash, 2008).

$\mathrm{Na}$ busca pelo enfretamento desses problemas, a influência de atores não governamentais na gestão pública foi crescendo e ganhando espaço no debate literário sobre governança pública (Bache \& Flinders, 2004; Bovaird, 2005). Estudiosos sugeriram que a governança pública poderia ser compreendida como uma mudança no modelo hierárquico tradicional, em direção a um sistema de criação de valores fruto da aprendizagem social mútua, do engajamento e da interação de grupos de interesse (Kallis, Kiparsky, \& Norgaard, 2009; Mah \& Hills, 2014; Provan \& Kenis, 2008). Apesar dessa evolução teórica, nas propostas de governança não se percebe a valorização desse processo de aprendizagem, haja vista a ausência da criação de estruturas e processos para tomada de decisão coletiva (Bryson et al., 2015).

Nesse contexto, a GC se apresenta como uma nova proposta, onde atores públicos e privados trabalham coletivamente, em uma tomada de decisão que se baseia em um consenso deliberativo, organizado de modo a permitir a resolução de problemas públicos complexos, que não poderiam ser tratados somente pelo governo (Ansell \& Gash, 2008; Choi \& Robertson, 2014a). Portanto, na esfera pública, pode-se interpretar que a colaboração será fruto da interação entre governo e sociedade na busca por soluções públicas, impossíveis de ser executadas por um único ator (Brown, Gong, \& Jing, 2012).

Assim, uma importante diferença da GC para outros modelos de governança pública é que não se trata de um processo meramente consultivo, mas uma via de mão dupla de comunicação e influência na tomada de decisão, de modo que a responsabilidade pelo alcance do objetivo em comum é compartilhada entre o público e o privado (Ansell \& Gash, 2008; Foster-Fishman et al., 2001; Weber \& Khademian, 2008). Destaca-se que essa ampla participação também implica uma responsabilização mútua que ultrapassa a divisão do público e do privado, ou seja, independentemente de qual seja o setor do qual o ator faça parte, ele deve sentir-se responsável pelos resultados (Freeman, 1997).

Diante da inclusão de tantas opiniões diversas, o consenso é assinalado claramente como um fator a ser buscado na GC. Isso porque deve haver a construção do convencimento de que certas decisões são mais vantajosas do que outras para a solução dos problemas, buscando o entendimento entre todos os participantes que divergem no processo (Ansell \& Gash, 2008; Robertson \& Choi, 2012).

A GC demanda compartilhamento de poder na tomada de decisões (Purdy, 2012) e tempo. É importante respeitar o tempo necessário para as inclusões dos participantes, a fim de construir a confiança dos membros ao longo do tempo, pois "certamente, o custo de retardar o processo de 
colaboração é alto, mas pode ser menor do que o custo associado com a perda de confiança" (Johnston, Hicks, Nan, \& Auer, 2010, p. 715).

Além disso, o essencial para essa proposta de governança é a participação e a colaboração no processo político daqueles que não pertencem ao governo (Bingham, 2010). Assim, a proposta difere de outros modelos de governança, pois nela o Estado não é necessariamente o líder ou o detentor dos processos decisórios e único responsável pelos resultados. É desejável que a liderança no processo colaborativo seja compartilhada entre gestores públicos, líderes comunitários, empresários, organizações parceiras ou quaisquer outros membros que tenham habilidades de mediação e comunicação transparente com os envolvidos (Newman et al., 2004; Weber \& Khademian, 2008). Com essa possibilidade de flexibilização na liderança, que ocorre tanto quando o ator estatal "fica fora do caminho" (Bryson et al., 2014, p. 448) como quando ele trabalha como um catalisador de parcerias, acontece um verdadeiro compartilhamento de responsabilidades e de poder propostos pela GC (McDougall et al. 2013; Weber \& Khademian, 2008).

Ao considerar o protagonismo estatal focado nos resultados, defendida na proposta da administração pública gerencial, percebe-se certa ambiguidade em termos de responsabilização, uma vez que os gestores públicos são responsáveis pelos resultados nesse caso, mas não podem gerenciar os processos políticos que permitem alcançá-los (Bryson et al., 2014; Moynihan, 2006). A accountability multifacetada, proposta pelo GC, por outro lado, proporciona a participação dos múltiplos atores nos processos políticos. Na accountability multifacetada, o Estado é chamado a reconhecer os valores e interesses do cidadão e este, por sua vez, a avaliar e construir políticas públicas exercendo sua capacidade de pressionar o governo a corrigir suas ações (Bryson et al., 2014; Newman et al., 2004). Essa accountability multifacetada deve fazer parte de um acordo formal entre os interessados, onde haja as definições claras de papéis, responsabilidades e mecanismos de execução e responsabilização (Ansell \& Gash, 2008; Siddiki et al., 2015).

\section{A TEORIA DA AÇÃO COMUNICATIVA}

Há um crescente movimento de estudos que vêm enfrentando a questão da hegemonia da racionalidade instrumental, que predominou por muito tempo na administração pública. Essa razão instrumental utiliza o método científico de causa e efeito, com foco na produtividade e em interesses imediatos, desprestigiando a intuição e o saber do pesquisador (Guerreiro Ramos, 1989). Sobre a hegemonia da racionalidade instrumental, é importante considerar a discussão da influência do positivismo na administração pública. Por exemplo, Box (2015) argumenta que a influência do positivismo e do funcionalismo afastou esse campo das noções de dialética, crítica e emancipação. A TAC, oferece um caminho para essa crítica, no entanto, sem desconsiderar a importância de processos racionais sistêmicos (Habermas, 2012a). De outra forma, Habermas (2012a) indica que a teoria dos sistemas e seus pressupostos sistêmicos e estratégicos devem ser considerados para a compreensão da sociedade. O conceito de CC trabalhado aqui pode ser operacionalizado analiticamente para ampliar essa discussão para além das dicotomias e da crítica mais "pessimista” de Box (2015).

Para Andion (2012), as mudanças paradigmáticas não foram suficientes para que a teoria das organizações e a administração pública rompessem com a concepção funcionalista. Na administração pública, essa concepção é caracterizada pela ausência de grandes mudanças nos padrões de relação entre Estado e sociedade. Isso porque, segundo Andion (2012), persistem o alto grau de centralização 
do poder no executivo, o isolamento (e insulamento burocrático) dos gestores públicos, a forte influência dos padrões patrimonialistas e o baixo poder de implementação das políticas públicas. Assim, para superar tais barreiras Andion (2012) sugere novos paradigmas, que não tenham foco no funcionalismo, para auxiliar na tarefa de reconfigurar a identidade da administração pública enquanto campo científico e trazer à tona novos pressupostos epistemológicos, teóricos e metodológicos para o campo.

O foco da TAC de Habermas na relação dialógica e intersubjetiva entre sujeitos da ação proporciona uma base explicativa das deficiências da teoria administrativa tradicional e oferece bases para a construção de formas emancipatórias, que se contrapõem à racionalidade instrumental, também criticada por Guerreiro Ramos (1989). Vale ressaltar que a intenção da TAC não é negar a razão como forma de emancipação, mas argumentar em prol da razão comunicativa.

Disso emerge a contribuição de Habermas (2012a), na proposta de uma teoria social que indica o caminho para a emancipação humana pela razão, por meio da relação intersubjetiva entre os indivíduos com foco na comunicação e na busca pelo entendimento compartilhado. Portanto, esse entendimento "remete a um comum acordo almejado pelos participantes e racionalmente motivado, que se mede segundo pretensões de validade criticáveis" (Habermas, 2012a, p. 147). É importante esclarecer que, para Habermas (2012a), esse "racionalmente motivado" está diretamente ligado às exteriorizações dos indivíduos, que são consideradas racionais quando há confiabilidade do saber nelas contido, de modo que possam ser fundamentadas e, também, sofrer críticas.

No mesmo sentido, ao falar dessas exteriorizações, há que se considerar suas pretensões de validade. Isso porque o argumento (exteriorização) deve buscar coerência com a realidade objetiva (verdade proposicional), deve ter elementos de referência social (correção normativa) e deve possibilitar a interpretação subjetiva dos indivíduos (veracidade) (Habermas, 2012a). Somente com base nessas pretensões se pode chegar ao entendimento linguístico, que é o fio condutor da racionalidade comunicativa. Dessa forma, se para Habermas (2012a, p. 481) a sentença somente será verdadeira se falantes e ouvintes compreenderem seu significado, "a semântica da verdade faz desdobrar a tese de que o significado de uma sentença é determinado por suas condições de verdade".

Vale ressaltar que os atos de fala (exteriorizações) não são apenas representações da linguagem (Habermas, 2012a). Se existem pressupostos já detalhados para a validade desses atos de fala, tais somente terão por base uma ação comunicativa se forem atos de fala ilocucionários - compreendidos como aqueles capazes de construir ações orientadas ao entendimento, estabelecendo uma ligação racionalmente motivada entre os sujeitos (Habermas, 2012a). Diferentemente dos atos de fala ilocucionários, orientados pelo entendimento, os atos perlocucionários são aqueles cuja ação é orientada ao êxito, diretamente ligados à ação teleológica (ação estratégica, utilitarista) e não à ação comunicativa. Já o ato locucionário é simplesmente o dizer, o falar (Habermas, 2012a). Portanto, o agir comunicativo é pautado por atos de entendimento (ilocucionários) e não por cálculos de êxito (perlocucionários).

Assim, a intersubjetividade só pode ocorrer por meio de um processo dialogicamente orientado, com predisposição ao consenso, construído por meio das esferas do mundo subjetivo, objetivo e social (Habermas, 2012a). A linguagem somente será válida se se referir aos três mundos (subjetivo, objetivo e social), na medida em que os falantes e ouvintes utilizam o sistema de referência desses mundos "como uma moldura interior da qual tecem e interpretam definições comuns relativas à situação de sua ação" (Habermas, 2012b, p. 221). Considerando ainda o mundo da vida que, para 
Habermas (2012a), é o pano de fundo da comunicação, onde acontece um consenso reflexivo a partir de sentidos compartilhados entre os participantes.

É por meio da reconstrução racional do ato de fala, tendo como pano de fundo o mundo da vida, que Habermas (2012a) almeja superar a racionalidade instrumental. Os pressupostos da fala são condição sine qua non para o agir comunicativo. Os quatro pressupostos para que a comunicação entre os indivíduos seja plena são: a) verdade proposicional (o que se faz e se fala é verdadeiro); b) veracidade (expressão sincera da subjetividade); c) correção normativa (adoção de princípios morais); e d) inteligibilidade (discurso compreensível) (Ferreira, 2005; Habermas, 2012a).

Se no diálogo o indivíduo é somente um meio para alcançar determinado fim, o que predomina é a racionalidade instrumental. Se, por outro lado, a busca for pelo entendimento mútuo baseado nas pretensões de verdade, veracidade, retidão e inteligibilidade, está-se diante da racionalidade comunicativa. Nas palavras de Ferreira (2005, p. 14), "é a partir do potencial de emancipação da competência comunicativa que se verifica a possibilidade de superação do egocentrismo implícito na racionalidade pretendida pela ação estratégica".

A partir de todo o exposto, as relações entre Estado, esfera pública, sociedade e democracia são pensadas por Habermas (1997) a partir da mudança paradigmática proposta pela TAC. Nisso, o autor defende um modelo procedimental de democracia: democracia deliberativa, pautada na troca de argumentos, na razão comunicativa e na esfera pública. Para Habermas (1997), a esfera pública, como esfera discursiva e comunicativa, torna-se relevante para a formação da opinião pública e a influência nas decisões do Estado pelas demandas da sociedade civil. Em decorrência disso, seu modelo democrático se aproxima em vários pontos da proposta de relação entre Estado e sociedade presente nos estudos de GC.

Este estudo se posiciona na proposição de uma abordagem analítica para a identificação de práticas de CC a partir das aproximações entre GC e TAC, apresentada a seguir.

\section{APROXIMAÇÕES ENTRE GOVERNANÇA COLABORATIVA E AÇÃO COMUNICATIVA}

Pode-se identificar constructos teóricos que têm fundamentos próximos tanto na GC como na TAC. Tais constructos possibilitam um ambiente colaborativo entre atores públicos e privados. Dessa forma, a fim de delinear as principais intersecções entre a GC e a TAC na construção da colaboração, delimitaram-se os quatro elementos recorrentes para a existência de um processo de colaboração segundo Ansell e Gash (2008), Innes e Booher (2010), Robertson e Choi (2012) e Choi e Robertson (2014a). Em cada um dos elementos se constroem as aproximações existentes entre a GC e a TAC.

\subsection{Multiplicidade de atores}

Há um amplo debate na literatura acerca de como o Estado deve atuar no enfrentamento dos problemas públicos. Uma dessas correntes defende o argumento da liderança estatal como instrumento de progresso social e econômico (Bielschowsky, 2012; Furtado, 2000). Por outro lado, quando se fala em GC e em novos designs de políticas públicas, o principal elemento apontado na literatura é a união de vários atores públicos e privados, possuidores de diferentes recursos e informações compartilhados durante a colaboração (Ansell \& Gash, 2008; Emerson et al., 2012; Howlett, 2014; Emerson \& Nabatchi, 2015; Mah \& Hills, 2014; Siddiki et al., 2015; Sullivan et al., 2006). Essa multiplicidade de 
atores enriquece o processo decisório e as possibilidades de atuação da rede colaborativa (Choi \& Robertson 2014a; Foster-Fishman et al., 2001). Além disso, a presença de múltiplos atores aumenta a legitimidade do processo colaborativo, uma vez que a união de várias visões e conhecimentos pode dar ensejo a soluções e regras de melhor qualidade, à construção de instrumentos de prestação de contas e a melhor compreensão dos desafios enfrentados por todos (Freeman, 1997; Innes \& Booher, 2010). O resultado é um verdadeiro diálogo colaborativo, onde toda a informação se torna crucial para o sucesso das ações (Innes \& Booher, 2010).

Se a multiplicidade de atores é tão importante para a GC, para a TAC esse constructo não ocupa menor destaque. Isso porque quando Habermas (2012a) explica o modo como se dá o entendimento linguístico, ele enfatiza que uma das condições é que falantes e ouvintes compreendam o significado de uma sentença na medida em que sabem sob quais condições a sentença é verdadeira.

Para Habermas (2012a, p. 547), "o conhecimento das condições de verdade consiste em saber como se constata se elas foram cumpridas ou não em dada situação". Assim, se a condição de verdade da sentença determina seu significado, também se exigem as figuras de falantes e ouvintes para que ocorra o entendimento linguístico. Portanto, o agir comunicativo exige interações mediadas pela linguagem nas quais todos os participantes buscam o entendimento linguístico, o que logicamente exige uma pluralidade de falantes e ouvintes para a construção da dialogicidade.

Ademais, a multiplicidade de atores é destacada por Habermas na TAC, quando ele esclarece que "o mundo só conquista objetividade ao tornar-se válido enquanto mundo único para uma comunidade de sujeitos capazes de agir e utilizar a linguagem" (Habermas, 2012a, p. 40), que o autor denomina comunidade de intérpretes. Dessa forma, resta claro que, para que a prática comunicativa possa ocorrer, é necessário um conjunto de interpretações pressupostas pelos integrantes a fim de alcançar o consenso almejado pela via comunicativa (Habermas, 2012a). Acrescenta-se no contexto da exigência de uma multiplicidade de atores para a constituição da ação comunicativa, a reflexão de Habermas $(2002$, p. 96) quanto à rede comunicativa que constrói "o meio através do qual se forma e se reproduz a cultura, a sociedade e as estruturas da personalidade".

Em relação a essa rede comunicativa, Habermas (2012b, p. 269) explica que "na perspectiva interna do mundo da vida, a sociedade se apresenta como uma rede de cooperações mediadas pela comunicação". Isso ocorre porque a sociedade é mediada por uma rede de atos ilocucionários, onde o mundo da vida é construído pelos membros a partir de tradições culturais comuns que coexistem com a sociedade. Nesse sentido, a multiplicidade de atores se encontra em um horizonte de possibilidades ilimitadas de entendimento, na medida em que a perspectiva dos membros acerca do mundo da vida seja fruto de um entendimento transparente e livre de qualquer violência (Habermas, 2012b).

\subsection{Interdependência}

No âmbito da GC, compreende-se por interdependência a ideia de que a solução dos problemas públicos depende do envolvimento de atores públicos e privados, em uma relação recíproca e orientada à entrega de valor público. Portanto, a interdependência se dá na perspectiva de enfrentamento dos problemas públicos e não na perspectiva unilateral de atores específicos, para os quais a colaboração não é condição sine qua non para sua existência (Ansell \& Gash, 2008; Bryson et al., 2015; Choi \& Robertson, 2014a; Emerson et al., 2012; Robertson \& Choi, 2012; Weber et al., 2007). Portanto, a GC deve ser construída com flexibilidade, já que a interpretação é de que 
o governo não é o único ator que tem obrigações de entrega de valor público e poder de decisão (Bryson et al., 2014; Purdy, 2012).

Essa via de comunicação é interpretada por Habermas (2012a) como o processo de reconhecimento intersubjetivo, necessário ao entendimento. O reconhecimento intersubjetivo ocorre quando cada indivíduo percebe que aquilo que o outro fala tem coerência diante da realidade (verdade proposicional), elementos de referência (correção normativa) e possibilidade de ser interpretado segundo critérios subjetivos (veracidade subjetiva). Se, para Habermas (2012a), o agir comunicativo é orientado pelo entendimento mútuo, isso implica que há interdependência entre as falas dos interlocutores que precisam reconhecer intersubjetivamente suas pretensões de validade.

Ao interpretar os elementos de uma racionalidade colaborativa, Innes e Booher (2010) esclarecem que a colaboração não é possível quando os atores afetados não são interdependentes e, portanto, não têm motivos para se envolver uns com os outros. Do contrário, quando os argumentos válidos e legítimos emanados pelos agentes são compreendidos, percebe-se a relação de interdependência entre os atores que a TAC exige. Isso porque tais argumentos são concebidos como um "prosseguimento reflexivamente direcionado do agir que se orienta por outros meios ao entendimento" (Habermas, 2012a, p. 61). O indivíduo não pode apresentar um agir comunicativo sem que ocorra a interação com o outro em um processo de encadeamento de falas e ações. Tais ações sociais, guiadas e inspiradas pelo diálogo entre os indivíduos, só podem ocorrer pela interdependência entre interpretação e entendimento dos atores, que acontece nos três mundos: a) objetivo (material); b) social (regulado por normas); e c) subjetivo (interior). É relevante considerar, ainda, que, para Habermas (2002), o agir comunicativo pressupõe um sentido que ele denomina rigorosamente intersubjetivo.

Diante das aproximações entre GC e TAC, pode-se dizer que a interdependência na colaboração ocorre quando os atores estatais oferecem argumentos verdadeiros no processo de formulação de políticas públicas e ações políticas que são, por sua vez, compreendidos pelos cidadãos após uma interação entre falas e ações em busca do entendimento.

\subsection{Processo deliberativo inclusivo}

O processo deliberativo inclusivo é uma característica intrínseca da GC e dos princípios democráticos e pode ser compreendido como muito mais do que a convocação e a oportunidade de participação de todos os envolvidos no processo (Choi \& Robertson, 2014a, 2014b; Elias \& Alkadry, 2011; Emerson \& Nabatchi, 2015; Purdy, 2012). Isso porque a deliberação deve ser inclusiva, na medida em que reconhece a capacidade das diversas opiniões para influenciar o processo de construção de tomadas de decisões (Ansell \& Gash, 2008; Foster-Fishman et al., 2001; Freeman, 1997; Johnston et al., 2010; Mah \& Hills, 2014; Newman et al., 2004; Weber \& Khademian, 2008). Portanto, "todo cidadão tem informação vital, especialmente sobre suas próprias experiências vividas nos processos de governança local" (Elias \& Alkadry, 2011, p. 879).

Evidentemente, nessa deliberação deve ocorrer entendimento mútuo, onde um acordo entre as partes não deve ser imposto: "não pode ser extorquido ao adversário por meio de manipulações" (Habermas, 2003, p. 165). Os envolvidos, então, precisam negociar sobre a situação e as consequências esperadas, harmonizando internamente seus planos de ação. Na GC, é importante a não imposição de interesses, principalmente os estatais (Ansell \& Gash, 2008). Isso porque os envolvidos devem ter o mesmo grau de representação e importância e o Estado não deve impor ou esforçar-se para que seus 
interesses se sobressaiam em detrimento dos interesses dos outros atores. Do contrário, estar-se-ia diante de um desequilíbrio de poder que não favorece a GC (Ansell \& Gash, 2008).

Assim, a negociação no processo deliberativo só pode ocorrer em um ambiente performativo da prática argumentativa, onde haja inclusividade quanto à participação de todos os interessados, igualdade de oportunidade de fala, veracidade quanto à convicção dos participantes no que dizem e ausência de coações, onde o argumento vencedor é aquele mais bem fundamentado por razões plausíveis - a força não coativa do melhor argumento. Com isso, Habermas (2014) define com clareza as condições de processo deliberativo inclusivo, com igualdade de participação e livre de coação. Por conseguinte, aqui não se considera a maioria em relação à minoria por meio do voto, mas o consenso alcançado via atos de fala ilocucionários, em busca do entendimento entre os participantes.

Independentemente de quantos sejam os participantes e da velocidade com que ocorrem as deliberações, Elias e Alkadry (2011, p. 875) explicam que os processos deliberativos podem começar com algumas ideias dispersas e aparentemente desconexas, mas que darão origem a um fluxo contínuo de outras ideias em "um processo pelo qual a lógica interna só pode ser compreendida a partir do processo, dos olhos e palavras daqueles que dele participam".

Um processo é colaborativamente racional, para Innes e Booher (2010, p. 6), "na medida em que todos os interesses afetados se envolvem conjuntamente no diálogo face a face, trazendo suas várias perspectivas para a mesa para deliberar sobre os problemas que enfrentam juntos". Ao invés de uma solução perfeita, os diversos atores envolvidos oferecem uma grande variedade de experiências, conhecimentos e ideias com muitas opções para se explorar (Innes \& Booher, 2010). O diálogo e a compreensão mútua no processo deliberativo reforçam a confiança e a motivação dos envolvidos nas práticas e nos espaços de CC (Choi \& Robertson, 2014b) e a fala livre de coação direciona os participantes na busca pelo entendimento (Habermas, 2014).

\subsection{Busca pelo consenso}

Quando se fala em consenso no contexto da GC, Buuren (2009) explica que seu processo de construção significa que os atores chegaram a um entendimento compartilhado sobre a identificação do problema e sua melhor solução. A necessidade desse entendimento também é destacada por Habermas (2002). $\mathrm{O}$ consenso na TAC remete a um entendimento racionalmente motivado. Significa que o consenso é fruto do entendimento, que somente pode ocorrer por meio do agir comunicativo - este, por sua vez, exige, além do uso da linguagem, outras condições para existir, como: construção cooperativa dos planos de ações entre os participantes; interpretações comuns das situações; e entendimento compartilhado (Habermas, 2002). Assim, esse consenso ocorre exatamente quando o ouvinte aceita uma oferta de fala do seu interlocutor, estabelecendo-se um comum acordo - este será, então, o "fundamento de uma coordenação consensual dos planos de ação a serem almejados por cada indivíduo" (Habermas, 2012a, p. 512).

Em outras palavras, o consenso, para Habermas (2012a), é o reconhecimento intersubjetivo da pretensão de validade que o falante une a uma exteriorização. As pretensões de validade estão diretamente ligadas às condições de verdade de um enunciado. Tanto é que Habermas (2012a, p. 481) explica que "falantes e ouvintes compreendem o significado de uma sentença quando sabem sob que condições a sentença é verdadeira". Tanto para a TAC como para a GC, o consenso é condição para o entendimento. Por outro lado, Innes e Booher (2010) ressaltam que, por mais que o consenso 
completo não possa ser alcançado, deve haver uma concordância substancial entre a maioria absoluta e todos os esforços devem ser feitos para encontrar formas criativas de satisfazer todos os participantes antes de encerrar o diálogo. As opiniões diversas, desse modo, apesar de inevitáveis, podem ser harmonizadas na medida que ocorre, por meio do processo dialógico livre de coação defendido pela TAC, o convencimento de que certas decisões são mais vantajosas para a rede como um todo (Robertson \& Choi, 2012).

Por conseguinte, para a TAC, "são os próprios atores que procuram o consenso e o medem conforme a verdade, a correção e a veracidade" (Habermas, 2012a, p. 192). Para que isso ocorra, o processo deliberativo inclusivo, com suas características de ampla participação e influência nas decisões, revela-se o melhor caminho na busca pelo consenso (Robertson \& Choi, 2012).

Realizadas, então, algumas aproximações teóricas entre GC e TAC, a próxima seção apresenta uma abordagem analítica de pesquisa a partir dessas interfaces.

\section{ABORDAGEM ANALÍTICA PARA ESTUDO DA COLABORAÇÃO COMUNICATIVA}

Um sistema de governança exige um regime democrático onde haja a participação da sociedade na elaboração de políticas públicas (Arturi, 2003). Segundo Habermas (2012a, pp. 155-156), "as pessoas que vivem em uma sociedade precisam situar-se nela tanto para alcançar o que querem quanto para evitar o que não querem". Nesse mesmo sentido, Faguet (2014) enfatiza que, enquanto nos países desenvolvidos a participação dos indivíduos na formação de organizações é cada vez maior, em países em desenvolvimento ocorre o contrário: um limitado acesso a determinados grupos na composição da sociedade civil organizada. É imprescindível repensar essa forma de participação social mais especificamente, identificando aproximações entre teorias como a GC e a TAC, que têm os pressupostos de multiplicidade de atores, interdependência, processo deliberativo inclusivo e a busca pelo consenso.

Ao aproximar a GC e a TAC na busca por constructos teóricos enfatizados por ambas teorias, percebe-se um pressuposto básico comum habermasiano: "as questões práticas podem ser decididas de uma forma precipuamente argumentativa" (Habermas, 2012a, p. 51). Fica claro que um processo, para ser denominado colaborativo, precisa reunir condições que levem a um direcionamento onde o entendimento deve ser privilegiado. Caso contrário, não se pode falar em CC. Isso porque há um pano de fundo que permeia os quatro elementos teóricos comuns: a comunicação dialógica. Innes e Booher (2010, p. 100) ressaltam que "o diálogo autêntico requer regras de base adotadas colaborativamente que permitirão um diálogo produtivo". Assim, "sem sinceridade e sem o questionamento de conhecimentos e pressupostos dados, um diálogo não pode ser colaborativamente racional" (Innes \& Booher, 2010, p. 100). Como se percebe, essas questões são próximas às discutidas pela TAC no que tange às pretensões de validade dos atos de fala.

É importante destacar que Habermas (2012b, p. 221) conceitua o agir comunicativo como "um processo de interpretação cooperativo em que os participantes se referem simultaneamente a algo no mundo subjetivo, no mundo social e no mundo objetivo". Percebe-se que esse agir se torna presente em espaços e práticas de CC. A propósito, Habermas (2002, p. 69) retoma esse assunto em outras de suas obras afirmando que os atos de fala orientados para o entendimento "não podem ser realizados sem a cooperação e o assentimento livre de um destinatário e que só podem ser explicados pelos recursos à ideia de entendimento que habita no interior do próprio meio linguístico". Portanto, "fins ilocucionários não podem ser atingidos por outro caminho que não seja o da cooperação" (Habermas, 2002, p. 68). 
Habermas (2002) defende que não se obtém a cooperação de modo individual. Há a necessidade do entendimento linguístico tão defendido pelo autor, na busca pelo consenso de soluções práticas. No entanto, tal cooperação não se compõe somente pela multiplicidade de atores. Soma-se à comunidade de intérpretes a necessidade da interdependência entre interpretação e entendimento linguístico, a inclusividade de participação sem coação e a busca pelo consenso por meio do entendimento compartilhado - elementos apontados por Ansell e Gash (2008), Innes e Booher (2010), Robertson e Choi (2012) e Choi e Robertson (2014a) para a construção da GC.

Pode-se afirmar que, para a GC em suas aproximações com a TAC, não basta que a administração pública preste informações aos envolvidos por meio de canais de participação e/ou contabilize as atividades. A sociedade precisa participar de um processo deliberativo inclusivo, com igualdade de participação e ausência de coação, onde o consenso é o resultado de um entendimento compartilhado de dada situação.

Com essa interação entre interessados e tomadores de decisão, as estruturas de governança se tornam mais permeáveis aos anseios sociais e ocorre um processo de auxílio mútuo em prol de objetivos comuns ou parcialmente diferenciados. Por outro lado, não se ignora a presença dos conflitos nesse processo. Eles existirão e a tônica do processo será a busca por soluções de problemas que dificilmente seriam alcançadas por um único ator (Brown et al., 2012). Dessa forma, a GC e a TAC desenham uma forma dialógica em busca do consenso em um plano real onde há divergências e conflitos.

Ainda sobre os possíveis conflitos na colaboração, Emerson et al. (2012) destacam que a importância do entendimento mútuo nesse momento se refere especificamente à capacidade de compreender e respeitar as posições e os interesses dos outros, mesmo diante da discordância. A propósito, Robertson e Choi (2012) ponderam que o diálogo, presente no processo deliberativo inclusivo, não precisa, necessariamente, ter um baixo índice de conflito, já que estimula o processo deliberativo e aumenta a satisfação dos participantes, na medida em que há concessões entre os interessados (Robertson \& Choi, 2012).

Baseando-se na ideia de que em um processo deliberativo inclusivo o conflito é algo inevitável, Elias e Alkadry (2011) trazem o conceito de conflito construtivo - que se baseia na integração das diferenças, onde as pessoas reconhecem que tais diferenças e semelhanças no grupo podem criar uma compreensão muito mais rica dos problemas e das soluções, o que não ocorreria em ações isoladas ou individuais. Nesse sentido, Habermas (1997) não elimina o conflito das relações humanas, mas defende que é possível superá-lo por meio da ação comunicativa, estabelecendo as bases de uma sociedade democraticamente emancipada.

A presença de conflitos, portanto, exigirão cada vez mais dos participantes o uso de argumentos fundamentados e também criticáveis, onde o comum acordo será sustentado por razões. E essa razão sempre deverá ser comunicativa, uma vez que jamais um conflito de opiniões deverá ser resolvido pelo emprego estratégico da violência (Habermas, 2012a). Se assim for, não se estará diante nem de um agir comunicativo nem da prática da CC.

Destaca-se, então, que é a primeira vez que se identificam aproximações teóricas entre a GC e a TAC para propor uma abordagem analítica com o intuito de direcionar estudos que almejam identificar espaços e práticas de CC. O Quadro 1 apresenta as categorias de análise, seu significado e as questões que podem nortear estudos empíricos. 


\section{QUADRO 1 ABORDAGEM ANALÍTICA PARA IDENTIFICAÇÃO DE PRÁTICAS DE COLABORAÇÃO COMUNICATIVA}

\begin{tabular}{|c|c|c|c|c|}
\hline \multicolumn{5}{|c|}{ Abordagem Analítica } \\
\hline Categorias & $\begin{array}{l}\text { Multiplicidade de } \\
\text { atores }\end{array}$ & Interdependência & $\begin{array}{l}\text { Processo deliberativo e } \\
\text { inclusivo }\end{array}$ & Busca pelo consenso \\
\hline $\begin{array}{l}\text { Síntese } \\
\text { conceitual }\end{array}$ & $\begin{array}{l}\text { O entendimento } \\
\text { linguístico exige } \\
\text { uma pluralidade de } \\
\text { falantes e ouvintes } \\
\text { para legitimarem o } \\
\text { processo colaborativo. }\end{array}$ & $\begin{array}{l}\text { A interdependência ocorre } \\
\text { quando os argumentos de } \\
\text { atores estatais e cidadãos } \\
\text { são compreendidos, após } \\
\text { uma interação de falas } \\
\text { e ações em busca do } \\
\text { entendimento. }\end{array}$ & $\begin{array}{l}\text { Na presença da } \\
\text { participação inclusiva, } \\
\text { sem coação, Estado e } \\
\text { sociedade viabilizam } \\
\text { espaços deliberativos. }\end{array}$ & $\begin{array}{l}0 \text { entendimento exige } \\
\text { os pressupostos da } \\
\text { verdade, da correção e } \\
\text { da veracidade, para que } \\
\text { mesmo com conflitos } \\
\text { se possa construir o } \\
\text { consenso. }\end{array}$ \\
\hline $\begin{array}{l}\text { Questões } \\
\text { centrais }\end{array}$ & $\begin{array}{l}\text { Quem são os atores } \\
\text { envolvidos? De onde } \\
\text { eles veem? Existe } \\
\text { representatividade } \\
\text { de diferentes } \\
\text { organizações? } \\
\text { Todos os possíveis } \\
\text { afetados pela decisão } \\
\text { participam do debate? }\end{array}$ & $\begin{array}{l}\text { Os atores compreendem } \\
\text { o que é dito? Quais são } \\
\text { os objetivos em comum e } \\
\text { quais são as divergências? } \\
\text { Os autores coordenam } \\
\text { suas ações de forma } \\
\text { conjunta? Como os atores } \\
\text { cooperam? As interações } \\
\text { se mantêm ou são } \\
\text { temporárias? }\end{array}$ & $\begin{array}{l}\text { Todos os atores foram } \\
\text { ouvidos? Quais as opiniões } \\
\text { que influenciaram a } \\
\text { tomada de decisão? } \\
\text { Quais argumentos foram } \\
\text { desconsiderados e } \\
\text { porquê? Foram observadas } \\
\text { relações de poder e } \\
\text { assimetrias? }\end{array}$ & $\begin{array}{l}\text { Os argumentos utilizados } \\
\text { são verdadeiros e } \\
\text { sinceros? Os atores estão } \\
\text { dispostos a ajustarem } \\
\text { as suas preferências? } \\
\text { Os atores chegaram a } \\
\text { acordos? As decisões } \\
\text { foram consideradas } \\
\text { legítimas por todos os } \\
\text { participantes? }\end{array}$ \\
\hline
\end{tabular}

Fonte: Elaborada pelos autores.

Ressalta-se que a proposta analítica desta pesquisa não visa a identificar um tipo ideal de governança ou modelo de arranjo entre Estado e sociedade. O processo de aprendizagem e o respeito às especificidades de cada espaço público são premissas da colaboração e suas complexidades desencorajam qualquer busca por um modelo ideal de governança. Por outro lado, o que se propõe é oferecer um ponto de partida para a reflexão acerca da possibilidade de identificar espaços propícios para práticas de CC.

\section{CONSIDERAÇÕES FINAIS}

As estruturas tradicionais de tomada de decisão estatal sem participação dos envolvidos ou com sua manipulação têm servido para aumentar os conflitos, as insatisfações sociais e os processos judiciais (Innes \& Booher, 2010). Os esforços do gerencialismo ratificaram o papel de um Estado centralizador e tradicional e as propostas de governança pública mantiveram o foco na contabilização de atividades desenvolvidas pelo Estado, sem construir processos de tomada de decisão coletiva. Enfim, reproduziuse uma lógica pautada na racionalidade instrumental de exclusão dos cidadãos e centralização estatal das decisões. 
Este estudo se propôs a construir uma abordagem analítica, a partir das aproximações entre a GC e TAC, para a investigação de práticas de CC entre Estado e sociedade. Tal esforço resultou na identificação de pressupostos de uma CC baseada na interação dialógica entre múltiplos atores, por meio de deliberações mediadas por argumentos racionais com vistas ao consenso.

Os achados do estado da arte da GC e das obras clássicas habermasianas demonstraram que os pressupostos de uma CC viabilizam ambientes propícios a uma participação social, inclusiva, sem coação. Assim, sociedade e atores estatais percebem que comungam de objetivos comuns e que as opiniões diferentes sobre as possíveis soluções podem iniciar um processo de aprendizagem social mútua. Sem ignorar os conflitos, sua superação se torna possível pelo processo dialógico proposto pela GC e pela TAC, no qual o uso da comunicação é o substituto da violência, da coação e da centralização. Com isso, a busca pela solução dos problemas públicos não é mais uma proposta unidirecional pelo Estado, mas fruto de uma deliberação consensual junto a outros atores sociais, onde haja um entendimento comum do que é o problema e os melhores caminhos para sua solução.

As perguntas norteadoras da abordagem analítica apresentada podem ser um ponto de partida para o(a) pesquisador(a) que, após a escolha da realidade a pesquisar, poderá direcionar seus esforços na identificação de práticas de CC entre Estado e sociedade. Os processos colaborativos são um desafio para países sem tradição de participação social nas decisões públicas. Por outro lado, são facilitadores de mudanças quando se está diante de problemas públicos complexos que exigem esforços múltiplos (Bryson et al., 2015). Ademais, a colaboração ajuda a tornar as instituições mais efetivas e adaptativas e torna o próprio sistema mais resiliente e mais permeável aos anseios sociais (Innes \& Booher, 2010).

Outra questão importante é que a GC se entrelaça com outras questões também presentes nos estudos de TAC. Bingham (2010), assim como Emerson et al. (2012), entende que a GC perpassa alguns assuntos, mas não se aprofunda em questões como: relações entre processo político e engajamento cívico, democracia deliberativa, gestão pública colaborativa e resolução de conflitos, entre outros temas que formam uma agenda para futuras pesquisas teórico-empíricas. Estudos sobre as convergências entre a proposta habermasiana de democracia deliberativa e a GC podem constituir objeto de futuros estudos para a compreensão dos elementos fundamentais da participação social e da deliberação pública. Pode-se tentar responder a seguinte questão:

- Como a CC poderia se estabelecer em arranjos entre Estado, mercado e sociedade civil? 


\section{REFERÊNCIAS}

Abreu, J. C. A. (2010). Modelos epistemológicos na administração pública: o discurso substantivo em Habermas acerca da democracia na sociedade da informação. Administração Pública e Gestão Social, 2(1), 1-20.

Alcântara, V. C., \& Pereira, J. R. (2017). O locus da gestão social no contexto das inter-relações e tensões entre mundo-da-vida (lebenswelt) e sistema (system). Organizações \& Sociedade, 24(82), 412-431.

Andion, C. (2012). Por uma nova interpretação das mudanças de paradigma na administração pública. Cadernos EBAPE.BR, 10(1), 1-19.

Ansell, C., \& Gash, A. (2008). Collaborative governance in theory and practice. Journal of Public Administration Research and Theory, 18(4), 543-571.

Arturi, C. S. (2003). Os desafios para a instauração de uma governança mundial democrática na atual conjuntura internacional. Indicadores Econômicos FEE, 31(1), 75-94.

Bache, I., \& Flinders, M. (2004). Multi-level governance. Oxford, England: Oxford University Press.

Bielschowsky, R. (2012). Estratégia de desenvolvimento e as três frentes de expansão no Brasil: um desenho conceitual. Economia $e$ Sociedade, 21(Especial), 729-747.

Bingham, L. B. (2010). The next generation of administrative law: building the legal infrastructure for collaborative governance. Wisconsin Law Review, 10(2), 297-356.

Bovaird, T. (2005). Public governance: balancing stakeholder power in a network society. International Review of Administrative Sciences, 71(2), 217-228.

Box, R. C. (2015). Critical social theory in public administration. Oxford, England: Routledge.

Brown, T. L., Gong, T., \& Jing, Y. (2012). Collaborative governance in mainland China and Hong Kong: introductory essay. International Public Management Journal, 15(4), 393-404.

Bryson, J. M., Crosby, B. C., \& Stone, M. M. (2014). Public value governance: moving beyond traditional public administration and the new public management. Public Administration Review, 74(4), 445-456.
Bryson, J. M., Crosby, B. C., \& Stone, M. M. (2015). Designing and implementing cross-sector collaborations: needed and challenging. Public Administration Review, 75(5), 647-663.

Buuren, A. V. (2009). Knowledge for Governance, Governance of Knowledge: Inclusive Knowledge Management in Collaborative Governance Processes. International Public Management Journal, 12(2), 208-235.

Choi, T., \& Robertson, P. J. (2014a). Caucuses in collaborative governance: modeling the effects of structure, power, and problem complexity. International Public Management Journal, 17(2), 224-254.

Choi, T., \& Robertson, P. J. (2014b). Deliberation and decision in collaborative governance: a simulation of approaches to mitigate power imbalance. Journal of Public Administration Research and Theory, 24(2), 495-518.

Couto, F. F., \& Carrieri, A. P. (2017). Habermas, the conceptual debates about public-privatesocial spheres and the communicative action in organizational theory. Revista de Administração, Contabilidade e Economia, 16(3), 827-844.

Elias, M. V., \& Alkadry, M. G. (2011). Constructive Conflict, Participation, and Shared Governance. Administration \& Society, 43(8), 869-895.

Emerson, K., \& Nabatchi, T. (2015). Evaluating the productivity of collaborative governance regimes: a performance matrix. Public Performance \& Management Review, 38(4), 717-747.

Emerson, K., Nabatchi, T., \& Balogh, S. (2012). An integrative framework for collaborative governance. Journal of Public Administration Research and Theory, 22(1), 1-29.

Faguet, J.-P. (2014). Decentralization and governance. World Development, 53, 2-13.

Ferreira, F. V. (2005). Ação comunicativa e estudos organizacionais. Revista de Administração de Empresas, 45(4), 10-21.

Foster-Fishman, P. G., Berkowitz, S. L., \& Lounsbury, D. W. (2001). Building collaborative capacity in community. American Journal of Community Psychology, 29(2), 241-261. 
Freeman, J. (1997). Collaborative governance in the administrative State. Ucla Law Review, 45(1), 1-98.

Furtado, C. (2000). O fator político na formação nacional. Estudos Avançados, 14(40), 7-12.

Guerreiro Ramos, A. (1989). A nova ciência das organizações: uma reconceituação da riqueza das nações. Rio de Janeiro, RJ: Ed. FGV.

Habermas, J. (1997). Direito e democracia: entre facticidade e validade. Rio de Janeiro, RJ: Tempo Brasileiro.

Habermas, J. (2002). Pensamento pós-metafísico. Rio de Janeiro, RJ: Tempo Brasileiro.

Habermas, J. (2003). Consciência moral e agir comunicativo. Rio de Janeiro, RJ: Tempo Brasileiro.

Habermas, J. (2012a). Teoria do agir comunicativo: racionalidade da ação e racionalização social (Vol. 1). São Paulo, SP: WMF Martins Fontes.

Habermas, J. (2012b). Teoria do agir comunicativo: sobre a crítica da razão funcionalista (Vol. 2). São Paulo, SP: WMF Martins Fontes.

Habermas, J. (2014). A ética do discurso. Lisboa, Portugal: Ed. 70.

Howlett, M. (2014). From the 'old' to the 'new' policy design: design thinking beyond markets and collaborative governance. Policy Science, 47, 87-207.

Innes, J. E., \& Booher, D. E. (2010). Planning with complexity: an introduction to collaborative rationality for public policy. Oxford, England: Routledge.

Johnston, E. W., Hicks, D., Nan, N., \& Auer, J. C. (2010). Managing the inclusion process in collaborative governance. Journal of Public Administration Research and Theory, 21(4), 699-721.

Kallis, G., Kiparsky, M., \& Norgaard, R. (2009). Collaborative governance and adaptive management: lessons from California's CALFED Water Program. Environmental Science \& Policy, 12(6), 631-643.

Kissler, L., \& Heidemann, F. G. (2006). Governança pública: novo modelo regulatório para as relações entre Estado, mercado e sociedade? Revista de Administração Pública, 40(3), 479-499.

Lara, L. G. A., \& Vizeu, F. (2017). A frankfurtianidade de Habermas e suas possibilidades em estudos organizacionais. In Anais do 40 Colóquio
Internacional de Epistemologia e Sociologia da Ciência da Administração. Florianópolis, SC.

Mah, D. N.-Y., \& Hills, P. (2014). Collaborative governance for technological innovation: a comparative case study of wind energy in Xinjiang, Shanghai, and Guangdong. Environment and Planning C: Government and Policy, 32(3), 509-529.

Matias-Pereira, J. (2010). A governança corporativa aplicada no setor público brasileiro. Administração Pública e Gestão Social, 2(1), 109-134.

Mcdougall, C. L., Leeuwis, C., Bhattarai, T., Maharjan, M., \& Jiggins, J. (2013). Engaging women and the poor: adaptive collaborative governance of community forests in Nepal. Agriculture and Human Values, 30(4), 569-585.

Moynihan, D. P. (2006). Managing for results in state government: evaluating a decade of reform. Public Administration Review, 66(1), 77-89.

Newman, J., Barnes, M., Sullivan, H., \& Knops, A. (2004). Public participation and collaborative governance. Journal of Social Policy, 33(2), 203-223.

Provan, K. G., \& Kenis, P. (2008). Modes of network governance: structure, management, and effectiveness. Journal of Public Administration Research and Theory, 18(2), 229-252.

Purdy, J. M. (2012). Framework for assessing power in collaborative governance processes. Public Administration Review, 72(3), 409-417.

Robertson, P. J., \& Choi, T. (2012). Deliberation, consensus, and stakeholder satisfaction. Public Management Review, 14(1), 83-103.

Sant’Anna, L. T., Tonelli, D. F., \& Abbud, E. B. (2016, setembro). Collaborative governance: a maturity level proposal based on a scoping study. In Anais do 40o Encontro da Associação Nacional de PósGraduação e Pesquisa em Administração. Mata de São João. BA.

Siddiki, S. N., Carboni, J. L., Koski, C., \& Sadiq, A.-A. (2015). How policy rules shape the structure and performance of collaborative governance arrangements. Public Administration Review, 75(4), 536-547. 
Sullivan, H., Barnes, M., \& Matka, E. (2006). Collaborative capacity and strategies in area-based initiatives. Public Administration, 84(2), 289-310.

Tenório, F. G. (1998). Gestão social: uma perspectiva conceitual. Revista de Administração Pública, 32(5), 7-23.

Tenório, F. G. (2005). (Re)visitando o conceito de gestão social. Desenvolvimento em Questão, 3(2), 101-124.

Tonelli, D. F., Sant'Anna, L., Abbud, E. B., \& Souza, S. A. S. (2018). Antecedents, process, and equity outcomes: a study about collaborative governance. Cogent Business \& Management, 5, 1-17.

Weber, E. P., \& Khademian, A. M. (2008). Wicked problems, knowledge challenges, and collaborative capacity builders in network settings. Public Administration Review, 68(2), 334-349.

Weber, E. P., Lovrich, N. P., \& Gaffney, M. J. (2007). Assessing collaborative capacity in a multidimensional world. Administration \& Society, 39(2), 194-220.

\section{Lindsay Teixeira Sant'Anna}

https://orcid.org/0000-0003-2311-111X

Mestre em Administração Pública pela Universidade Federal de Lavras (UFLA); Doutoranda em Administração pela Universidade Federal de Lavras (UFLA); Professora na Faculdade Adventista de Minas Gerais (FADMINAS). E-mail lindsaysantanna@gmail.com

\section{Valderí de Castro Alcântara}

https://orcid.org/0000-0002-6698-0609

Doutor em Administração pela Universidade Federal de Lavras (UFLA); Professor da Universidade do Estado de Minas Gerais (UEMG). E-mail: valderidecastroalcantara@gmail.com

\section{José Roberto Pereira}

https://orcid.org/0000-0003-1570-2016

Doutor em Sociologia pela Universidade de Brasília (UnB); Professor Titular do Departamento de Administração e Economia da Universidade Federal de Lavras (DAE/ UFLA). E-mail: jrobertopereira2013@gmail.com

\section{Mônica Carvalho Alves Cappelle}

iD

https://orcid.org/0000-0002-0095-3405

Doutora em Administração pela Universidade Federal de Minas Gerais (UFMG); Professora Associada do Departamento de Administração e Economia da Universidade Federal de Lavras (DAE/UFLA).

E-mail: edmo@ufla.br

\section{Dany Flávio Tonelli}

https://orcid.org/0000-0002-4307-6430

Doutor em Administração pela Universidade Federal de Lavras (UFLA); Professor adjunto IV do Departamento de Administração e Economia da Universidade Federal de Lavras (DAE/UFLA). E-mail: danytonelli@gmail.com 